\title{
Prenatal Cocaine Exposure: Long-Run Effects and Policy Implications
}

\author{
Lawrence M. Berger \\ Columbia University \\ Jane Waldfogel \\ Columbia University
}

In this article, we review the literature regarding prenatal cocaine exposure and child development. We then reexamine current child welfare policies in light of that literature, paying particular attention to laws that mandate reporting substance-exposed newborns and substance use during pregnancy as well as policies that view such reports as prima facie evidence of child maltreatment. Finally, we reassess the utility of such policies, given our current knowledge of the long-term effects of prenatal exposure, and consider alternative approaches to protecting children who are born to parents who are using crack cocaine.

The "crack epidemic" that began in the mid-1980s has been associated with an increase in the number of children exposed to cocaine in utero. The Office of the Inspector General estimates that 100,000 children are born prenatally exposed to crack cocaine each year (Hawley et al. 1995); others have estimated this figure to be somewhere between 40,000 and 375,000 (Mayes and Bornstein 1995). ${ }^{1}$

Widespread use of the drug has also resulted in an increased number of children in the child welfare system (Besharov 1990; National Association of Public Welfare Administrators [NAPCWA] 1991; Barth 1994; Sabol 1994). Following decreases in the early 1980s, the number of children in foster care rose sharply in the late 1980s. Studies of several large states have indicated that drug use by parents was a leading reason for the increase in placements; studies have also found a direct relationship between cocaine use and prenatal exposure and reports to child protec- 
tive services (CPS). ${ }^{2}$ This latter relationship is not surprising given that several states have legislation making prenatal exposure to cocaine a mandatory report to CPS.

Although children exposed prenatally to crack cocaine-so-called crack babies - are just the tip of the iceberg of the broader class of children who are affected by their parents' substance abuse (Gardner and Young 1997), they are the most visible and the most reported group. ${ }^{3}$ The fact that a newborn can be tested to determine his or her mother's recent substance use provides a unique opportunity to identify a child affected by parental substance use. In addition, both the mandatory reporting laws in place in several states and explicit policies governing the acceptance of reports of substance-exposed children as prima facie cases of child maltreatment in other states have made the period immediately following birth an opportune time to report a family to CPS. Moreover, many professionals involved in substance-abuse treatment believe that a child's birth is a critical moment for intervention with the user, a moment when she is most likely to be motivated to pursue treatment. In short, while parental cocaine use affects children of all ages, it is newborns who have been increasingly likely to be referred to CPS and placed in foster care as a result of the crack epidemic. ${ }^{4}$ Children under 1 year old accounted for 23 percent of all children entering care in 1994, compared to only 12 percent in 1977 (U.S. Department of Health and Human Services 1997; see also Goerge and Wulczyn 1998/99).

The impact of prenatal cocaine exposure on infants has been extensively studied. However, recent reviews of the literature show that much of the research to date has been found to be contradictory, unreliable, biased, or inconclusive. We know the least about the long-term effects of prenatal exposure. Studies that follow prenatally exposed children into their preschool and school-age years are only now becoming available, and they have tended not to support many of the assumptions that were previously made about the developmental limitations of children prenatally exposed to cocaine (Robins and Mills 1993; Barth 1994; Zuckerman 1994; Hawley et al. 1995; Needlman et al. 1995; Frank et al. 1996; Lester et al. 1996; Mayes 1996; Lester, LaGasse, and Bigsby 1998). Such substantial gaps in the literature point to a lack of information with which to accurately predict the long-term effects of prenatal exposure on children's growth and development.

In this article, we review the current literature regarding the effects of prenatal cocaine exposure on child development and reexamine current child welfare policies in light of the findings from that literature. We consider, in particular, laws that mandate reporting substance-exposed newborns and substance use during pregnancy as well as policies that accept such reports as prima facie evidence of child maltreatment. These laws and policies have been the popular response to the dilemma of how to handle crack-exposed children. In light of the current evidence, we reassess their utility and consider other approaches to the problem of 
protecting children who are born when their parents are using crack cocaine. While we primarily focus on children who are prenatally exposed to crack cocaine, our discussion of screening, testing, and social policies relating to prenatal exposure to cocaine may have broader implications for addressing parental substance abuse in general.

\section{Review of Current Literature}

\section{Myths and Media Monsters}

When the use of crack cocaine first came to public attention, many observers predicted "bleak futures" for crack-exposed children, assuming that they would be "seriously impaired," "difficult to manage," and would suffer considerable medical complications as a result of their exposure (Hawley et al. 1995, p. 364). Media reports, often based on nonscientific and anecdotal evidence, presented the children as both helpless and hopeless and resulted in widespread myths about these children and their developmental possibilities. The following passages are typical of how these children were portrayed in major media outlets in the late 1980s and early 1990s:

One of the infants in the sterile hospital room wailed disconsolately, frantically flailing its tiny arms and legs as children born to crack-using mothers often do (Treaster 1993, p. 1; emphasis added).

He sometimes erupts into frenzied episodes of thrashing about, pulling his hair, biting and banging his head against a wall (Toufexis 1991, p. 58).

[He] has spent his whole life crying. He is jittery and goes into spasms when he is touched. His eyes don't focus. He can't stick out his tongue, or suck (Newsweek, July 28, 1986; cited in Myers, Olson, and Kaltenbach 1992, p. 2).

[He] has been awake for days. He cries inconsolably, and his tiny limbs jerk and jitter constantly. Periodically, his hands fly back to the sides of his head and his large, dark eyes freeze wide in startled terror (Readers Digest, February 1991; cited in Myers et al. 1992, p. 2).

The "crack-baby" label came to imply that prenatally exposed children faced devastating developmental prognoses and would fare poorly in school and later life (Daley 1991; Griffith 1992; Mayes et al. 1992; Zuckerman and Frank 1992; Zuckerman 1994; Zuckerman and Frank 1994; Hawley et al. 1995). The sense that crack-exposed children's futures were determined by their prenatal exposure was so strong that these children were even referred to as a "bio-underclass." 5

As the first cohort of crack-exposed children began reaching school age, the media reported that they were "presenting problems that have left many kindergarten teachers confused and exhausted" (Daley 1991, p. A1). One teacher was described as being so frustrated with a crack- 
exposed second grader that she threatened to resign if the child was not removed from her classroom (Sluder, Kinnison, and Cates 1996/97). Other teachers predicted that if crack-exposed children were placed in regular classrooms, they would "kill somebody" or "hurt everybody" (Cohen and Erwin 1994, p. 246).

Many of these reports, myths, and assumptions were largely conceived before crack-exposed children reached school age, and they have yet to be supported by empirical research. Indeed, researchers in the 1990s began to challenge many of the early assumptions about prenatally exposed children. In particular, recent research has challenged three common yet erroneous assumptions: (1) that all prenatally exposed children are severely affected by exposure, (2) that little can be done to help these children, and (3) that their medical, behavioral, and learning problems are directly caused by prenatal exposure (Griffith 1992).

In contrast to what was initially thought, it now appears that a considerable proportion of the outcomes associated with prenatal exposure can be overcome through competent caregiving in appropriate environments. Recent studies have concluded that postnatal environmental factors may play a crucial role in influencing developmental outcomes by either helping exposed children to overcome biological vulnerabilities or by placing them at greater risk of harm (see, e.g., Mathias 1992; Zuckerman and Frank 1992; Azuma and Chasnoff 1993). Prenatally exposed children who receive warm and responsive care and are nurtured in supportive environments seem to be able to develop well (Mathias 1992; Zuckerman and Frank 1992). Conversely, children whose mothers continue to use crack cocaine after their births may be at substantially elevated risk of poor development, in large part due to the adverse effects of living with an addicted mother.

Finally, many of the outcomes that were once attributed solely to prenatal exposure to crack cocaine have recently been linked to both confounding variables and methodological shortcomings in the studies themselves. It now appears that previous studies have tended to overestimate the effects of prenatal exposure on newborns as well as its longterm effects on children's growth and development (Lutiger et al. 1991; Chasnoff et al. 1992; Mayes et al. 1992; Hutchings 1993; Frank et al. 1996). ${ }^{6}$

\section{Methodological Issues}

The extent to which children are affected by crack exposure in utero is difficult to determine for several reasons. First, the vast majority of children who are prenatally exposed to crack cocaine have also been prenatally exposed to alcohol, tobacco, or other drugs, each of which may contribute to some of the outcomes that are sometimes solely attributed to crack exposure (Lutiger et al. 1991; Hutchings 1993; Richardson and 
Day 1994; Hawley et al. 1995; Lester et al. 1996; Lester, LaGasse, and Bigsby 1998). Yet many studies have not controlled for prenatal use of other substances.

Second, there is an interplay between prenatal exposure and adverse socioeconomic circumstances, including poverty, poor home environments, and other factors that may contribute to poor outcomes for children (van Baar 1990; Kliegman et al. 1994; Richardson and Day 1994). ${ }^{7}$ Observers have criticized studies on the grounds that they have not been able to separate the effects of prenatal exposure from those of lack of prenatal care, poor maternal health, inadequate prenatal nutrition, social disadvantage, and other correlates of poverty (Chasnoff 1992; Chasnoff et al. 1992; Robins and Mills 1993; Zuckerman and Frank 1994; Hawley et al. 1995; Lester, Freier, and LaGasse 1995; Mayes and Bornstein 1995; Neuspiel 1995; Olson et al. 1995; Frank et al. 1996; Hans 1996; Lester et al. 1996; Mayes 1996). These factors, coupled with the fact that poor and black women are much more likely to be identified as prenatal users than are white middle- and upper-class women, have meant that the children studied have tended to be at elevated risk for negative perinatal outcomes for many reasons other than the direct effect of their prenatal exposure to cocaine (Kliegman et al. 1994; Richardson and Day 1994). ${ }^{8}$

A third limitation is that studies have not been able to completely control for other "lifestyle issues" that result when a pregnant woman is living in, and a child is born into, a "drug-seeking environment" of "chaos and flux" (Chasnoff 1992, p. 307). In their interviews with crackaddicted mothers, Hawley et al. (1995) found that many of the women reported that they were negligent or dysfunctional caregivers when using drugs. The following passages illustrate their responses: "I didn't care about nothin' but how I was going to get [drugs]. I didn't supply their needs too good. I didn't wash their clothes, I didn't do nothin' I was supposed to do when I was usin'." "I would more or less push them aside, um, be mean to them, you know, 'cause I didn't want them around me. . . . I didn't want them to see me doin' what I was doin' " (Hawley et al. 1995, p. 372). ${ }^{9}$

Fourth, a variety of methodological concerns have been raised relating to studies of this population. Possible undetected exposure of control group infants and children may threaten the validity of results, particularly for those studies that rely on either maternal self-reports or urine testing to document exposure. Self-reported patterns of use are difficult, if not impossible, to verify. Urine testing, which, in conjunction with selfreport, is the most common detection method used, detects only cocaine metabolites within 48-72 hours of use, providing little information about dosage, frequency, and chronicity of use. Meconium testing can be used to reveal use in the more distant past (back to 20-weeks gestational age) but has been much more rarely used (Chasnoff 1992; Barth 
and Needell 1996; Frank et al. 1996).${ }^{10}$ When self-report or urine tests are employed to identify prenatally exposed children, control groups may include children who were exposed days, weeks, or months before their mothers were tested as well as those exposed children whose mothers deny using. Such undetected exposure in control groups may limit any observable developmental differences between exposed and (supposedly) nonexposed children, resulting in an underestimation of the negative effects of prenatal exposure. In addition, many current studies focus on experimental group children whose mothers participated in substance-abuse treatment or stopped using cocaine during the study period-factors that could influence results by reducing the amounts and, therefore, observable effects of exposure (Chasnoff et al. 1992; Azuma and Chasnoff 1993; Hawley et al. 1995). ${ }^{11}$

Conversely, difficulties controlling for dosage, other drug use, route and timing of administration, and passive postnatal exposure (factors that have further prevented researchers from firmly linking specific developmental outcomes to the timing and amounts of prenatal exposure) suggest that some studies may have resulted in overestimations of the adverse developmental effects of prenatal exposure. Finally, the generalizability of studies of prenatally exposed children has also been limited by inadequate or inconsistent measures and study designs, sample selection biases, sampling and measurement problems, high rates of attrition, and small sample sizes (Chasnoff 1992; Robins and Mills 1994; Zuckerman and Frank 1994; Hawley et al. 1995; Lester et al. 1995; Neuspiel 1995; Olson et al. 1995; Frank et al. 1996; Lester et al. 1996; Mayes 1996; Lester, LaGasse, and Bigsby 1998).

\section{What Have We Learned?}

Keeping in mind the potentially confounding effects of environmental and socioeconomic factors, as well as the methodological problems summarized above, what can we conclude about the effects of cocaine exposure in utero on subsequent child development? Most studies have focused on newborns and tend to find that cocaine-exposed infants are more likely than others to be born prematurely and to exhibit low birth weight, decreased length, and small head circumference (Chasnoff et al. 1989; Chasnoff et al. 1992; Azuma and Chasnoff 1993; Kliegman et al. 1994). ${ }^{12}$ It is unclear, however, whether these effects are lasting. While some studies have reported that prenatal exposure to crack permanently affects growth, others have found no permanent effects. For example, a study conducted by Ira Chasnoff and colleagues found that exposed infants who exhibited low birth weight and decreased length caught up to control infants on these factors by age 1 (Chasnoff et al. 1992; Azuma and Chasnoff 1993).

Evidence regarding the effects of cocaine exposure on other infant 
outcomes is much less certain. Although prenatal exposure has, particularly in earlier studies, sometimes been associated with spontaneous abortion, abruptio placentae, intrauterine growth retardation, intraventricular hemorrhage, abnormal growth patterns, apnea, sudden infant death syndrome, genitourinary tract malformations, and neurobehavioral deficiencies, each of these effects may be confounded by other substance use, poor nutrition, and poor prenatal care (Hutchings 1993; Robins and Mills 1994). Cocaine exposure in utero has also been linked to poorer outcomes for infants (and sometimes toddlers) in terms of organizational skills, language development, congenital malformation and perinatal mortality, emotional and behavioral functioning, visual recognition memory, neurobehavioral capabilities, attachment and peer relations, interactive abilities, self-regulation capacities, responses to external stimuli, cognitive development, and motor development/motor coordination (Chasnoff et al. 1985; Chasnoff et al. 1989; van Baar 1990; Chasnoff et al. 1992; Hansen, Struthers, and Gospe 1993; Singer et al. 1994; Beckwith et al. 1995; Hawley et al. 1995; Barth and Needell 1996; Bayer et al. 1996; Calhoun and Alforque 1996; Johnson et al. 1997; Lester, LaGasse, and Bigsby 1998). Such outcomes, however, have not been consistently observed, and these findings have largely been challenged by later studies. ${ }^{13}$ Recent studies have found that, controlling for socioeconomic variables and other drug use, (1) prenatal cocaine exposure appears not to significantly affect infant growth and morphology (Richardson and Day 1994), and (2) even the most impaired cocaine-exposed infants do not differ behaviorally from other neurologically impaired infants (Schutter and Brinker 1992).

Fewer studies have followed cocaine-exposed children beyond infancy. We could find only 12 studies that followed children beyond the first year of life and only nine that followed children to age 3 or higher. Despite sharing some of the same limitations as many of the infant studies, these longitudinal studies have the advantage of tracking children's development over time. Thus they should be given more weight when considering the evidence regarding the long-term effects of prenatal exposure to crack cocaine. Although these longitudinal studies report mixed results, our review of the evidence below suggests that there are indeed links between prenatal exposure to cocaine and later developmental problems.

Some of these studies found essentially no long-run effects of prenatal exposure to cocaine. Laura Guisti's (1996) study of exposed and nonexposed foster children ranging in age from 12 to 28 months found no significant developmental differences between the two groups, although both groups exhibited developmental scores that were below the national norm. Ellen Franck (1996) studied children under 5 years old in out-of-home care in New York City and concluded that the prenatally exposed children in her sample did not significantly differ from nonexposed children in terms of developmental delays. Scott Azuma and Chas- 
noff followed a group of cocaine-exposed children, and non-exposed controls, to age 3. The cocaine-exposed infants were found to have smaller head circumferences at birth and at 18 months of age, but cognitive development did not differ between the two groups at 18 months nor were there any significant differences in developmental outcomes between the exposed and control children at age 2 or age 3 (Azuma and Chasnoff 1993).

However, most of the longitudinal studies have found at least some long-run effects of prenatal cocaine exposure or have noted that the effects may have been too subtle for them to capture. For instance, in their study of exposed and nonexposed foster children between the ages of 1 and 4, Kimberly Yolton and Rosemary Bolig (1994) found that the two groups did not differ in terms of temperament, play behaviors, or adaptive behaviors. However, the exposed children in this study scored lower than controls in terms of conceptual development, and they displayed more physically violent behaviors. Hawley et al. (1995) report that the exposed children in their studies presented generally normal scores related to overall development and exhibited few differences from nonexposed children in terms of cognitive and language development through age 5 , but the researchers caution that there may have been differences not detected by their developmental measures. The exposed children, for instance, required more sessions to complete the developmental assessment because they seemed easily distracted and required coaxing to engage in the test activities.

Barry Lester and his colleagues note in their 1998 review that of the five studies using standardized tests to track cognitive development in cocaine-exposed children ages 3-6, only one found significant differences between cocaine-exposed children and nonexposed controls (and that study was conducted in the Netherlands on a population of children whose mothers had used heroin and methadone in addition to cocaine) (Lester, LaGasse, and Bigsby 1998). ${ }^{14}$ However, they found more evidence related to impaired language development. Of the seven studies that included a language assessment of children ages 3-6, five found statistically significant differences between cocaine-exposed and nonexposed children, with exposed children performing more poorly (Angelilli et al. 1994; Malakoff, Mayes, and Shottenfeld 1994; Nulman et al. 1994; van Baar and de Graaff 1994; Bender et al. 1995). These longer term, follow-up studies also provide some evidence that exposed children differ from nonexposed children regarding visual motor integration and sustained attention to tasks (Bender et al. 1995; Hawley et al. 1995; Richardson, Conroy, and Day 1996). Such findings led Lester and his colleagues to conclude that "as a group, children who have been exposed prenatally to cocaine are heterogeneous, displaying no consistent patterns of developmental deficiency. In fact, many function well within the average range for intelligence and adaptive skills. Differences 
in their development seem to cluster around attention, language comprehension, and emotional and behavioral regulation" (Lester, LaGasse, and Bigsby 1998, p. 139)..$^{15}$

Most recently, Chasnoff and colleagues' (1998) longitudinal study (completed after the review by Lester, LaGasse, and Bigsby [1998]) concluded that behavioral characteristics of 4-6 year olds were directly affected by prenatal exposure, resulting in higher rates of depression and anxiety; social, thought, and attention problems; delinquent and aggressive behaviors; and impulsivity and distractibility among prenatally exposed children. In terms of cognitive effects, the researchers found that while prenatal exposure did not directly affect the IQ scores of these children, their IQ scores were indirectly affected through the quality of their home environments: children living in homes in which there was prenatal substance use had poorer quality home environments, a factor that was related to lower IQ scores (Chasnoff et al. 1998).

Although the effects of cocaine exposure in utero may be less dire than anticipated on the basis of the earlier infant studies, the more recent longitudinal studies suggest that it would be a mistake to assume that prenatally exposed children are not at risk. A common theme in the literature is that cocaine exposure rarely occurs in isolation. Adding to the biological risks of both prenatal exposure to cocaine and prenatal exposure to other substances that are frequently used with cocaine, environmental factors have been found to "play a decisive part in determining development-either helping the child to overcome the [biological] vulnerability [created by prenatal exposure] or placing the child at greater risk of harm" (Mathias 1992, p. 14). Children who have neither experienced multiple child welfare placements nor continued to live with drug addicted mothers have been shown to have more positive outcomes than those living in homes where there is continued drug use (Griffith, Azuma, and Chasnoff 1994). ${ }^{16}$ In contrast, prenatally exposed children often develop poorly when faced with inadequate care from a mother whose functioning is affected by the "stress and chaos" that are associated with long-term drug abuse (Mathias 1992, p. 15). Studies have found that prenatal exposure and the postnatal environment have similar effects on the intelligence of 3 year olds (Azuma and Chasnoff 1993) and that maternal postpartum drug use is correlated with IQ and behavioral problems for children at age 6 (Chasnoff et al. 1998).

Barry Zuckerman and Deborah Frank caution that the "biologic vulnerability" presented by prenatal exposure "may render a child more vulnerable to the effects of poor caretaking" (Zuckerman and Frank 1992, p. 337). They cite studies of both opiate-exposed children and other children with potential nervous-system vulnerabilities in which family stability, responsive caretaking, and the quality of the postnatal environment were found to be significant predictors of developmental outcomes. Thus, poor caregiving environments may help to explain 
many of the poor developmental outcomes that have been observed among prenatally exposed children, while appropriate, responsible caregiving environments may help to compensate for the effects of exposure by significantly improving such outcomes. In short, the use of crack cocaine not only affects children directly through prenatal exposure but also indirectly through its adverse effects on both parenting behaviors and the families and communities in which these children live (Mayes et al. 1992).

At the same time, there is also some evidence that early intervention can make a difference for these children. Studies have found that prenatally exposed children who have access to early interventions, and for whom other major risk factors have been reduced, seem completely normal in terms of intellectual, social, emotional, and behavioral development at age 3 (Chasnoff 1992; Griffith 1992). The other major risk factors include inadequate prenatal care, inadequate prenatal nutrition, continued parental drug use, potential postnatal drug exposure, chaotic lifestyles (which may be further complicated by poverty), inconsistent or inadequate parental caregiving, multiple caregivers or placements, and maternal depression. Interventions such as substance-abuse treatment and early home visiting, combined with appropriate social service referrals, may help to reduce these risk factors. ${ }^{17}$ For instance, drug treatment during pregnancy may lead to greater participation in prenatal care activities as well as to improved prenatal nutrition. Furthermore, drug treatment during and after pregnancy may reduce parental drug use after birth and, consequently, the risk of postnatal drug exposure. It is also reasonable to expect that reduced parental drug use, in combination with early home visiting or similar in-home interventions, may result in less chaotic lifestyles, improved caregiving, reduced numbers of child protective services interventions and foster care placements, and decreased maternal depression. Finally, referral to appropriate social services may help mediate the socioeconomic problems, such as poverty and unemployment, that may place many substance-abusing and childwelfare-involved families at a further disadvantage. Appropriate social services referrals may also afford prenatally exposed children greater access to specialists who may aid them in reducing the effects of those biological vulnerabilities (e.g., cognitive, behavioral, emotional, and verbal) that may be related to prenatal exposure.

Thus, we can tentatively conclude, drawing on our still limited knowledge of the long-term effects of prenatal exposure to crack cocaine, that such exposure may indicate that a family is in need of intervention and is at risk of drawing child protective services attention, which may result in foster care placement. ${ }^{18}$ At the same time, there is evidence to suggest that children who are exposed to cocaine prenatally could benefit from early assessment and intervention. 


\section{The Child Welfare Response}

As our knowledge about cocaine-exposed children has evolved, so too has the response of the child welfare system. The influx of cocaineexposed children has affected the child welfare system in many ways. ${ }^{19}$ When the full impact of the crack epidemic began to crystallize in the late 1980s, observers like Douglas Besharov called it the "single toughest issue facing child welfare agencies" (Besharov 1989, p. 7). And, although cocaine use seems to have plateaued in the $1990 \mathrm{~s}$, the number of children affected-and their impact on the child welfare system-are still staggering. Besharov (1996) estimates that about the same number of children-between 30,000 and 65,000-were born prenatally exposed to cocaine in 1994 as in 1987 . These children constitute a large share of the child welfare caseload. A 1994 General Accounting Office study of young foster children in California, New York, and Pennsylvania, for instance, found that two-thirds had been prenatally exposed to drugs or alcohol, compared to only about 25 percent 5 years earlier (U.S. General Accounting Office 1994).

How has the child welfare system responded to the children exposed to cocaine in utero, and given what we now know about these children, how should the child welfare system respond? Here we look at two key aspects of the system's response: legislation regarding reporting and legislation regarding testing or screening. We focus on these two aspects of child welfare policy because legislation regarding reporting and testing or screening has been considered by many states, and by the Congress, as a first step in responding to the problem of crack babies. ${ }^{20}$

\section{Current Status of Laws regarding Reporting and Testing or Screening}

All states have mandatory reporting laws that both define child abuse and neglect and require doctors, teachers, and other professionals who come into contact with children to report suspected cases to CPS. In many states, infant drug addiction at birth has long been considered a reportable type of abuse or neglect. Thus, when the crack epidemic first hit and children were born prenatally exposed to crack cocaine, a natural response on the part of the child welfare system was to revise reporting laws to require filing an abuse-and-neglect report when a child was born having been prenatally exposed to cocaine, as evidenced by a positive toxicology test (often referred to as a positive "tox" or "toxic screen") or withdrawal symptoms at birth. By 1990, six states had passed such laws (National Center for Youth Law 1995). Illinois, for instance, required doctors to report any child who tested positive for drugs at birth. Minnesota went beyond the Illinois model by also requiring that physicians report positive drug tests on pregnant women. Between 1990 and 1995, several additional states - including Iowa, Wisconsin, and In- 
diana-amended their reporting laws to require that drug-exposed newborns be reported. Other states explicitly decided that positive toxic screens would not require the filing of a report. California passed a law to this effect in 1995, while New York simply changed its policy in 1990.

At the present time, although several states require that drug-exposed newborns be reported to child protective services, only Minnesota requires certain newborns to be tested for exposure to illicit drugs. In all other states, testing is discretionary, and rules regarding testing are established by hospitals and physicians. Whether it would be advantageous to move toward more uniform policies with regard to testing is controversial. A few years ago, then Representative Susan Molinari proposed legislation in Congress that would have required all newborns to be tested for substance exposure. This bill was opposed by child welfare groups and was never enacted; however, similar proposals may be made in the future.

An alternative to mandatory testing, proposed by Chasnoff, is that primary-care physicians screen every family with infants or young children as a means of promoting early detection of exposure. He recommends that whenever an infant or young child is born with or presents with a positive urine toxicology or whenever a young child's family is identified as abusing alcohol or illicit drugs, the family be referred for appropriate treatment but not referred to CPS unless the family refuses or fails to comply with treatment (Chasnoff 1998). This proposal has numerous advantages over a testing proposal but is also not entirely problem free, as we address below.

Should testing be mandated for all newborns? Is screening a better option? How should the system respond if a child tests or screens positive? Is mandatory reporting to CPS a sensible response, or would a first response by someone other than CPS be preferable? Drawing on what we now know about outcomes for cocaine-exposed children, we consider these questions below.

\section{Should Testing Be Mandated for All Newborns?}

There are many arguments to be made in favor of universal testing for all newborns. ${ }^{21}$ The current system, in which newborns are tested only if the physician recommends it, surely misses many children who are exposed to substances and who, if identified, could benefit from early intervention and treatment. Furthermore, the current system is inequitable: poor and minority children are much more likely to be tested even though nonpoor and white children are about equally as likely to be exposed to drugs or alcohol. Since a positive test result, at least under the current system, usually leads to involuntary state intervention, it matters whether or not families are inequitably subjected to that intervention.

There are also many arguments against universal testing. First, a test- 
ing system, if not perfect, could turn up false positives (cases that test positive when a child is not substance exposed). Such cases would, under the current system, receive unnecessary and undesirable intervention from CPS. An imperfect system could also produce false negatives (cases that test negative when a child is substance exposed), which would result in some children missing out on interventions that they should have received. In deciding whether testing makes sense, then, it is important to know how reliable the tests are likely to be. It is also important to know what size the exposed population is likely to be, as that factor also affects the shares of false positives and false negatives that are likely to occur.

Following the framework set out by Richard Light (1973) in his analysis of child protection policies, we use probability theory to evaluate whether testing could be sufficiently reliable given our knowledge of the accuracy of existing tests and the incidence of prenatal exposure. In this framework, the effectiveness of a national testing policy primarily depends on the following three factors: (1) the level to which our instruments can accurately identify instances in which exposure has occurred, (2) the level to which our instruments can accurately identify instances in which exposure has not occurred, and (3) the national incidence of prenatal exposure.

We have no firm data with which to predict the abilities of potential testing instruments to accurately identify both exposure and nonexposure. Therefore, we use a range of possibilities to investigate the ways in which different levels of testing accuracy affect the proportion of error that would result if a national testing policy were to be implemented. In order to do this, let us assume that our testing instruments will correctly identify exposure between 70 percent and 99 percent of the time. We will call this proportion $P(E)$. We will also assume that our instruments will correctly identify nonexposure between 80 percent and 99 percent of the time. ${ }^{22}$ We will call this proportion $P(N)$. Finally, since estimates of the incidence of prenatal exposure vary so widely, we should also look at the ways in which different incidence rates influence the effectiveness of the potential policy. We will call the incidence rate $P(I)$.

In order to determine-at various levels of the aforementioned proportions - (1) the proportion of children who are actually prenatally exposed and are identified as being exposed by the testing instruments, $P\left(P_{1} \mid D_{1}\right)$, and (2) the proportion of children who are actually exposed but are not identified by the testing instruments as being exposed, $P\left(P_{1} \mid D_{2}\right)$, we use Bayes's Theorem as follows:

$$
\begin{aligned}
& P\left(P_{1} \mid D_{1}\right)=\frac{P\left(P_{1}\right) P\left(D_{1} \mid P_{1}\right)}{P\left(P_{1}\right) P\left(D_{1} \mid P_{1}\right)+P\left(P_{2}\right) P\left(D_{1} \mid P_{2}\right)} \\
& P\left(P_{1} \mid D_{2}\right)=\frac{P\left(P_{1}\right) P\left(D_{2} \mid P_{1}\right)}{P\left(P_{1}\right) P\left(D_{2} \mid P_{1}\right)+P\left(P_{2}\right) P\left(D_{2} \mid P_{2}\right)},
\end{aligned}
$$


where

$P\left(P_{1}\right)=$ proportion of children who are prenatally exposed;

$P\left(P_{2}\right)=$ proportion of children who are not prenatally exposed;

$P\left(D_{1}\right)=$ proportion of children who are identified as prenatally exposed;

$P\left(D_{2}\right)=$ proportion of children who are not identified as prenatally exposed;

$P\left(D_{1} \mid P_{1}\right)=$ proportion of children identified as prenatally exposed given that they are actually exposed;

$P\left(D_{1} \mid P_{2}\right)=$ proportion of children identified as prenatally exposed given that they are not actually exposed;

$P\left(P_{1} \mid D_{1}\right)=$ proportion of children who are actually exposed given that they are identified as exposed;

$P\left(P_{1} \mid D_{2}\right)=$ proportion of children who are actually exposed given that they are not identified as exposed.

Since $P(E)$ is equal to the proportion of exposed children who are correctly diagnosed at first testing, $P(N)$ is equal to the proportion of nonexposed children who are correctly diagnosed at first testing, and $P(I)$ is equal to the proportion of children who are born prenatally drug exposed, the following substitutions can be made:

$$
\begin{aligned}
P\left(P_{1} \mid D_{1}\right) & =\frac{P(I) P(E)}{P(I) P(E)+[P(1-P(I)) \times P(1-P(N))]} \\
P\left(P_{1} \mid D_{2}\right) & =\frac{P(I) P(1-P(E))}{P(I) P(1-P(E))+(P(1-P(I)) \times P(N))} .
\end{aligned}
$$

By substituting various levels of $P(E), P(N)$, and $P(I)$ into this equation, we can compute the proportions displayed in table 1 and table 2 .

The figures on these tables provide appropriate probabilities for evaluating the potential effects of a national testing policy. For example, assuming that the instruments used for testing are precise, we could set $P(E)$ at .95 , indicating that exposure is correctly detected 95 percent of the time. We could also set $P(N)$ at .99 , indicating that nonexposure is correctly detected 99 percent of the time. We consider several alternative incidence rates. We begin with an example that uses a moderate incidence rate, which we set at 5 percent because it is estimated that between 1 percent and 10 percent of newborns (between 45,000 and 375,000 of the approximately 3.9 million children born annually) are exposed to cocaine in utero. In the next example, we reduce our estimated incidence rate to 1 percent, which may be more accurate for a low-incidence hospital or practice. In our final example, we estimate the incidence rate at 15 percent, which, while it is beyond the upper bound of most national 
Table 1

Proportion of Children Identified as Prenatally Exposed at First Testing Who Are ACtually Exposed

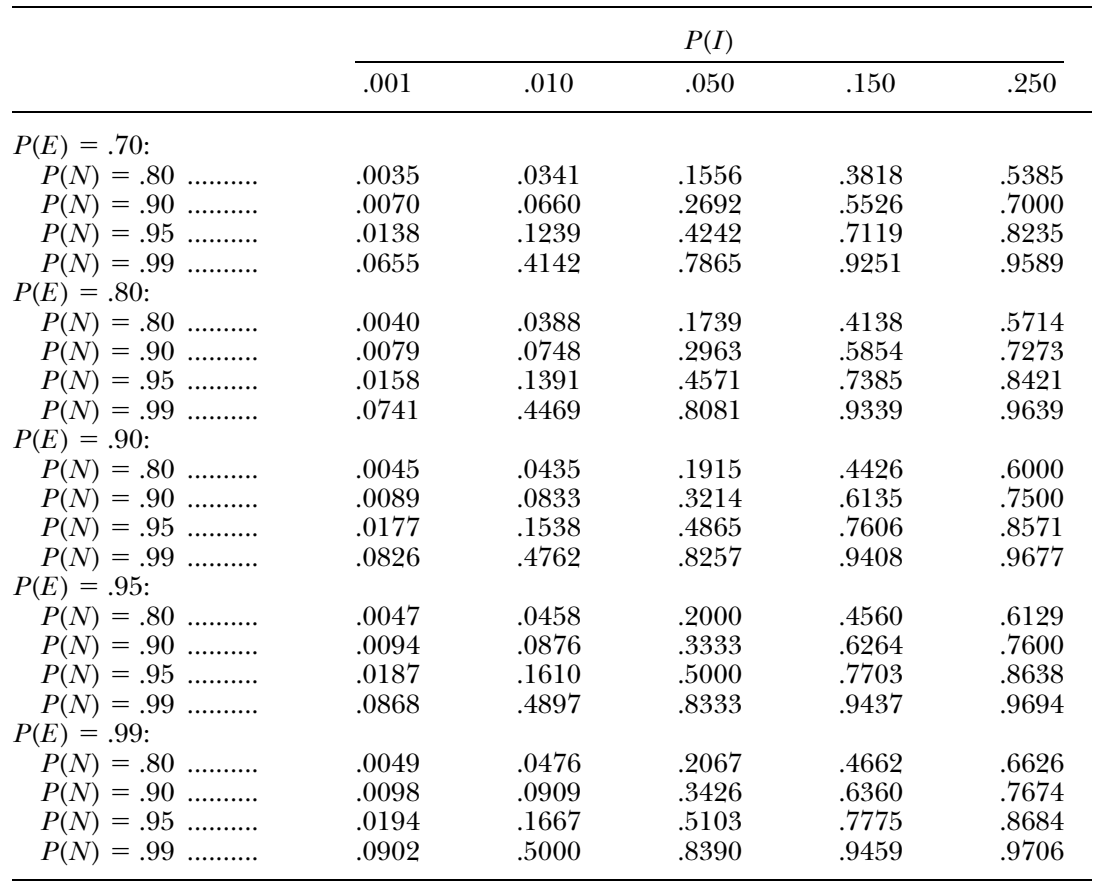

NotE.- $P(E)=$ proportion of exposed children who are correctly diagnosed at first testing; $P(N)=$ proportion of nonexposed children who are correctly diagnosed at first testing; $P(I)=$ proportion of children who are born prenatally exposed.

estimates of prenatal cocaine exposure, has been reported at high-risk hospitals. ${ }^{23}$ In addition, we show in the tables (but do not discuss in the text) two more extreme examples of very low and very high incidence rates ( 0.1 percent and 25 percent, respectively).

In our first example, assuming a moderate incidence of exposure, we could estimate $P(I)$ at .050 , indicating a 5 percent incidence rate. The number in table 1 that corresponds to these figures is .8333. This means that over 83 percent of the children identified as prenatally exposed would actually be exposed. If this were the case, the policy would result in false positives almost 17 percent of the time. Falsely identifying approximately 17 of every 100 children as having been prenatally drug exposed appears high and may or may not be an acceptable level of error. (The level of acceptability of error would partly depend on what happens once a child is identified as being exposed. This issue will be discussed in the next section.) At the same time, table 2 reveals that, under these 
Table 2

Proportion of Children Not Identified as Prenatally Exposed at First Testing Who Are Actually Exposed

\begin{tabular}{|c|c|c|c|c|c|}
\hline & \multicolumn{5}{|c|}{$P(I)$} \\
\hline & .001 & .010 & .050 & .150 & .250 \\
\hline \multicolumn{6}{|l|}{$P(E)=.70:$} \\
\hline$P(N)=.80 \ldots \ldots \ldots$ & .0004 & .0038 & .0194 & .0621 & .1111 \\
\hline$P(N)=.90 \ldots \ldots \ldots$ & .0003 & .0034 & .0172 & .0556 & .1000 \\
\hline$P(N)=.95 \ldots \ldots \ldots$ & .0003 & .0032 & .0163 & .0528 & .0952 \\
\hline$P(N)=.99 \ldots \ldots \ldots$ & .0003 & .0031 & .0157 & .0508 & .0917 \\
\hline \multicolumn{6}{|l|}{$P(E)=.80$} \\
\hline$P(N)=.80 \ldots \ldots \ldots$ & .0003 & .0025 & .0130 & .0423 & .0769 \\
\hline$P(N)=.90 \ldots \ldots \ldots$ & .0002 & .0022 & .0116 & .0377 & .0690 \\
\hline$P(N)=.95 \ldots \ldots \ldots$ & .0002 & .0021 & .0110 & .0358 & .0656 \\
\hline$P(N)=.99 \ldots \ldots \ldots$ & .0002 & .0020 & .0105 & .0344 & .0631 \\
\hline \multicolumn{6}{|l|}{$P(E)=.90$} \\
\hline$P(N)=.80 \ldots \ldots \ldots$ & .0001 & .0013 & .0065 & .0216 & .0400 \\
\hline$P(N)=.90 \ldots \ldots \ldots$ & .0001 & .0011 & .0058 & .0192 & .0357 \\
\hline$P(N)=.95 \ldots \ldots \ldots$ & .0001 & .0011 & .0055 & .0182 & .0339 \\
\hline$P(N)=.99 \ldots \ldots \ldots$ & .0001 & .0010 & .0053 & .0175 & .0326 \\
\hline \multicolumn{6}{|l|}{$P(E)=.95$} \\
\hline$P(N)=.80 \ldots \ldots \ldots$ & .0001 & .0006 & .0033 & .0109 & .0204 \\
\hline$P(N)=.90 \ldots \ldots \ldots$ & .0001 & .0006 & .0029 & .0097 & .0182 \\
\hline$P(N)=.95 \ldots \ldots \ldots$ & .0001 & .0005 & .0028 & .0092 & .0172 \\
\hline$P(N)=.99 \ldots \ldots \ldots$ & .0000 & .0005 & .0027 & .0088 & .0166 \\
\hline \multicolumn{6}{|l|}{$P(E)=.99$} \\
\hline$P(N)=.80 \ldots \ldots \ldots$ & .0000 & .0001 & .0007 & .0022 & .0041 \\
\hline$P(N)=.90 \ldots \ldots \ldots$ & .0000 & .0001 & .0006 & .0020 & .0037 \\
\hline$P(N)=.95 \ldots \ldots \ldots$ & .0000 & .0001 & .0006 & .0019 & .0035 \\
\hline$P(N)=.99 \ldots \ldots \ldots$ & .0000 & .0001 & .0005 & .0018 & .0034 \\
\hline
\end{tabular}

Note.- $P(E)=$ proportion of exposed children who are correctly diagnosed at first testing; $P(N)=$ proportion of nonexposed children who are correctly diagnosed at first testing; $P(I)=$ proportion of children who are born prenatally exposed.

assumptions, there is less than a 1 percent chance (.0027) of producing false negatives or failing to identify children who are actually exposed.

Using another example, if we again assume that $P(E)$ and $P(N)$ are .95 and .99 , respectively, and that $P(I)$ is more likely to be .01 , as may be the case in a low-incidence hospital or practice, then the corresponding figure in table 1 is .4897. This means that over half of the children that the testing process would identify as exposed really would not have been exposed. This is certainly an unacceptable level of error. What should be noted, moreover, is that in this scenario, the probability of false-positive diagnoses would exceed that of accurate diagnoses. This is because, as the estimated incidence rate decreases, even relatively small error rates in our testing instruments result in a large number of false-positive identifications. As indicated in table 1, only the combination of extremely precise methods for detecting both exposure and nonexposure and a relatively large incidence rate results in levels of error that may be ac- 
ceptable. Again, however, the number of false-negative errors that would occur is very low (.05 percent). The number of false-negative identifications resulting from a national testing policy may, in fact, be too high only if the prenatally exposed population is very large and our measuring instruments are relatively inaccurate.

Even if we assume that we could identify both exposure and nonexposure with 99 percent accuracy and even if the incidence of exposure was as high as 15 percent, as may be the case in a high-incidence hospital or practice, a national testing policy would still identify about five children out of 100 as being prenatally exposed when they are not. Only .18 percent of exposed children would be falsely identified as nonexposed given these proportions.

\section{Implications for Child Welfare Policy}

While the information presented here suggests that a national prenatal exposure testing policy has very little chance of being effective given our current estimates of incidence rates and testing accuracy, this may not necessarily be the case. Instead, we must balance the evidence that early identification and intervention may help to improve prenatally exposed children's developmental outcomes with the possibility that a national testing policy would result in a large proportion of false positives. While this analysis indicates that a national testing policy can not be the only method of identifying prenatally exposed children, it could certainly constitute one stage of a multistage process for doing so (as we discuss in the following section). As Light (1973) suggests, the first stage of such a process would focus on not missing real cases of exposure (not producing false negatives), while other stages would employ more stringent criteria for minimizing the number of false positives. Minimizing false positives becomes extremely important when such errors result in adverse legal and child welfare outcomes for the families involved. In many states, when a child is identified as having been prenatally exposed, one of three outcomes is likely to occur: (1) a child welfare investigation is initiated, (2) the child is removed from the home, or (3) criminal charges are brought against the birth mother. Whether or not we agree that these outcomes are appropriate under circumstances in which there is actual exposure, the possibility that a family would face such outcomes when exposure has not occurred must be held to an absolute minimum.

\section{Is Screening a Better Option?}

Many of the same arguments that have been made either for or against testing apply to screening as well. However, many physicians see screening as a better option. Is this the case? Many factors (such as ease of administration, accuracy, and cost) may influence which method and, indeed, which specific instrument is chosen, and other factors may play 
a significant role in the debate over such policies. ${ }^{24}$ However, when we consider the question in light of the framework used above, it becomes clear that screening is a preferred option only if (1) its results are likely to be more accurate than those of testing (or equally accurate but at a reduced cost) or (2) screening can be used as a first stage of a multistage testing strategy.

Would screening be more accurate? Drug and alcohol treatment professionals endorse the use of screening instruments such as the Substance Abuse Subtle Screening Inventory (SASSI) and claim that it can correctly identify substance abuse in 94 percent of cases. Current best estimates also suggest that screening instruments such as the SASSI might also incorrectly identify substance abuse - that is, produce false positives - in about 6 percent of cases. ${ }^{25}$ These figures suggest that a screening instrument, such as the SASSI, would do better than testing at identifying substance-exposed newborns if we assume that tests correctly identify 95 percent of substance-exposed newborns but that they incorrectly identify 11 percent of nonexposed newborns (Schwartz et al. 1990). ${ }^{26}$

However, it may be incorrect to think of screening merely as an alternative to testing. With regard to newborns, screening and testing could be complementary policies. For instance, a medical practice might first screen all pregnant women for substance abuse and then test only those newborns whose mothers screened positive or who showed signs of prenatal exposure to drugs or alcohol. (In addition, it might be prudent to test newborns whose mothers received no prenatal care and were therefore never screened.)

Such a multistage policy offers several advantages. It gives the physician a chance to counsel a pregnant woman about the risks of substance abuse and to refer her for drug or alcohol treatment if she screens positive during the pregnancy. It may also provide a better basis for deciding which newborns should be tested at birth. ${ }^{27}$ Furthermore, there is some evidence that pregnant women may be more likely to accurately report their substance use if they believe that the substance-using activities that they report (or fail to report) during the screening process will be verified via testing. ${ }^{28}$

Thus far in our discussion, we have not specified what type of intervention the children identified via screening or testing should receive. We turn to that question next.

\section{How Should the System Respond If a Child Tests or Screens Positive?}

In considering this question, it will be useful to examine separately the two different groups of children we have discussed thus far: newborns who test positive for exposure to cocaine and newborns whose mothers screened positive for cocaine during the pregnancy. 
For newborns who test positive for exposure to cocaine, it is now standard practice, and indeed law in most jurisdictions, that the case is reported to CPS. However, not all of these cases are substantiated for abuse or neglect by CPS, and only a minority of the children reported are removed from their mothers and placed into substitute care. This is because, in order to intervene beyond the point of an investigation, CPS must find not only that the mother used or is using crack cocaine but that her drug use is interfering with her ability to properly care for the child. Some women manage to provide adequate care in spite of their drug use, often by relying on friends or family members to provide some care for their children.

\section{Is Mandatory Reporting to CPS a Sensible Response?}

Given the evidence presented above, it would make sense that a case should be referred to CPS only if a child has tested positive and there are indications that the mother cannot adequately care for him or her. (This is not to say that infants who test positive should not be referred elsewhere for services; however, CPS may not be the most sensible referral.) All children who test positive could be referred for (1) substance abuse treatment for the parent(s) and (2) an assessment for the child in order to determine whether or not the child may require a developmental intervention such as home visiting by a nurse or social worker trained in early intervention with substance-exposed children. ${ }^{29}$ Physicians may also wish to closely monitor such children in case developmental problems surface in later childhood. Cases in which there is evidence at birth that the mother cannot adequately care for the child should continue being referred to CPS. However, without such evidence, cases should be referred to CPS only when the substance-abuse treatment worker or home-health visitor have concerns that warrant protective intervention.

Such models are already in place in several communities that are attempting to provide more sensible responses to substance-exposed newborns and their families. Jacksonville, Florida, for instance, refers all substance-exposed newborns to nurse home visitors with special expertise in substance abuse rather than to CPS. Chicago, Illinois, uses a mixed strategy, whereby cases may either be referred to CPS and a substance-abuse agency or to the substance-abuse agency alone, depending on whether the family needs both substance-abuse treatment and protective oversight or substance-abuse treatment alone. Implementing these different models of practice requires some degree of retraining of child welfare, child and family service, and health-care professionals. While a full discussion of this issue is beyond the scope of this article, we note that cross training - whereby child welfare, child and family service, and health-care staff are trained jointly with substance-abuse and early interventions specialists — would be particularly helpful in this regard..$^{30}$ 
As we discussed earlier, screening may also be used to identify exposure to cocaine before a child is born. How should those cases be handled? For those children identified prenatally, screening presents an excellent opportunity for a physician both to offer counsel and refer the mother for treatment prior to giving birth. It can also provide additional evidence to help a physician determine whether or not a child should be drug tested at birth or monitored and referred for further assessments or interventions (e.g., early intervention, home-visiting programs, substance-abuse treatment, or CPS) after birth.

\section{Conclusion}

The biological risks associated with prenatal exposure to crack cocaine are, thankfully, less severe than was first thought when crack cocaine burst onto the scene a little over a decade ago. Yet there is still substantial evidence for concern about children who are prenatally exposed to cocaine, particularly if they continue to live with a drug-using parent after birth. Identifying prenatally exposed children and providing them with appropriate interventions are sound policies, although not all means to this end are equally effective. As our analysis reveals, universal testing is one of the least promising policy alternatives. In contrast, more widespread screening of pregnant women and newborns - with the option of testing only those newborns whose mothers were identified as likely substance users through a screening instrument, who exhibit withdrawal symptoms, or who received no prenatal care-makes a good deal of sense. We do not, however, recommend that all children identified via screening or testing be referred to child protective services. The first line of defense in parental substance-abuse cases should be substance-abuse treatment services and, when there is additional evidence that a child's development may be compromised, assessment and referral to early intervention specialists such as home visitors. Child protective services should be involved only in those cases in which parents either refuse to participate in such services and, as a result, their children's well-being is compromised or where parents are unable to provide adequate caregiving, even after receiving services.

\section{References}

Angelilli, M. L., H. Fischer, V. Delaney-Black, M. Rubinstein, J. W. Ager, and Robert J. Sokol. 1994. "History of In Utero Cocaine Exposure in Language-Delayed Children." Clinical Pediatrics 33 (9): 514-16.

Azuma, Scott D., and Ira J. Chasnoff. 1993. "Outcome of Children Prenatally Exposed to Cocaine and Other Drugs: A Path Analysis of Three-Year Data." Pediatrics 92 (3): 396-402.

Barth, Richard P. 1994. "Long-Term In-Home Services.” Pp. 175-93 in When Drug Addicts Have Children: Reorienting Child Welfare's Response, edited by Douglas J. Besharov and 
Kristina W. Hanson. Washington, D.C.: Child Welfare League of America and American Enterprise Institute.

Barth, Richard P., and Barbara Needell. 1996. "Outcomes for Drug Exposed Children Four Years Post Adoption." Children and Youth Services 18 (1/2): 37-56.

Bayer, Dewey J., Bruce Bleichfeld, Shelly J. Lane, Martin A. Volker, Barbara Alif, and Brian Floss. 1996. "The Relationship between the Movement Assessment of Infants and the Fagan Test of Infant Intelligence in Infants with Prenatal Cocaine Exposure." Pp. 14553 in Children with Prenatal Drug Exposure, edited by Lynette S. Chandler and Shelly J. Lane. New York: Hawthorn.

Beckwith, Leila, Senobia Crawford, Jacqueline A. Moore, and Judy Howard. 1995. “Attentional and Social Functioning of Preschool-Age Children Exposed to PCP and Cocaine In Utero." Pp. 286-303 in Mothers, Babies, and Cocaine: The Role of Toxins in Development, edited by Michael Lewis and Margaret Bendersky. Hillsdale, N.J.: Erlbaum.

Bender, Suzanne L., Carol O. Word, Ralph J. Diclemente, Mary R. Crittenden, Nalini A. Persaud, and Lynn E. Ponton. 1995. "The Developmental Implications of Prenatal and/or Postnatal Crack Cocaine Exposure in Preschool Children: A Preliminary Report." Developmental and Behavioral Pediatrics 16 (6): 418-24.

Besharov, Douglas J. 1989. "The Children of Crack: Will We Protect Them?” Public Welfare 47 (4): 6-11.

- 1990. "Crack Children in Foster Care.” Children Today 19 (4): 21-25.

. 1996. "The Children of Crack: A Status Report.” Public Welfare 54 (1): 32-37.

Calhoun, George, Jr., and Minerva Alforque. 1996. "Prenatal Substance Afflicted Children: An Overview and Review of the Literature." Education 117 (1): 30-38.

Chasnoff, Ira J. 1992. "Cocaine, Pregnancy, and the Growing Child." Current Problems in Pediatrics 22 (7): 302-21.

$\rightarrow$. 1998. "Silent Violence: Is Prevention a Moral Obligation?" Pediatrics 102 (1): $145-48$.

Chasnoff, Ira J., Amy Anson, Roger Hatcher, Herb Stenson, Kai Iaukea, and Linda A. Randolph. 1998. "Prenatal Exposure to Cocaine and Other Drugs: Outcome at Four to Six Years." Annals of the New York Academy of Science 846: 314-28.

Chasnoff, Ira J., William J. Burns, Sidney H. Schnoll, and Kayreen A. Burns. 1985. "Cocaine Use in Pregnancy." New England Journal of Medicine 313 (11): 666-69.

Chasnoff, Ira J., Dan R. Griffith, Catherine Freier, and James Murray. 1992. "Cocaine/Polydrug Use in Pregnancy: Two Year Follow-Up.” Pediatrics 89 (2): 284-89.

$\rightarrow$ Chasnoff, Ira J., Dan R. Griffith, Scott MacGregor, Kathryn Dirkes, and Kayreen A. Burns. 1989. "Temporal Patterns of Cocaine Use in Pregnancy: Perinatal Outcome." Journal of the American Medical Association 261 (12): 1741-44.

Chasnoff, Ira J., Harvey J. Landress, and Mark E. Barrett. 1990. "The Prevalence of IllicitDrug or Alcohol Use during Pregnancy and Discrepancies in Mandatory Reporting in Pinellas County, Florida." New England Journal of Medicine 322 (17): 1202-6.

Cohen, Shirley, and Elizabeth J. Erwin. 1994. "Characteristics of Children with Prenatal Drug Exposure Being Served in Preschool Special Education Programs in New York City." Topics in Early Childhood Special Education 14 (2): 232-53.

Collett, Camille. 1997. "Major Trial Finds Only Subtle Fetal Injury from Cocaine." Journal of NIH Research 9: 30-32.

Daley, Suzanne. 1991. "Born on Crack and Coping with Kindergarten." New York Times, February 7.

$\rightarrow$ Famularo, Richard, Robert Kinscherff, and Terence Fenton. 1992. "Parental Substance Abuse and the Nature of Child Maltreatment." Child Abuse and Neglect 16 (4): 475-83.

Franck, Ellen J. 1996. "Prenatally Drug-Exposed Children in Out-of-Home Care: Are We Looking at the Whole Picture?" Child Welfare 75 (1): 19-34.

$\rightarrow$ Frank, Deborah A., Karen Bresnahan, and Barry S. Zuckerman. 1996. "Maternal Cocaine Use: Impact on Child Health and Development." Current Problems in Pediatrics 26 (2): $49-76$.

Frank, Deborah A., and Barry S. Zuckerman. 1993. "Children Exposed to Cocaine Prenatally: Pieces of the Puzzle." Neurotoxicology and Teratology 15 (5): 298-300.

Future of Children. 1993. 3 (3).

Future of Children. 1999. 9 (1).

Gardner, Sid, and Nancy Young. 1997. "Alcohol and Drug Treatment: An Essential Ingre- 
dient in Community Partnerships for Child Protection." Paper prepared for the Harvard Executive Session on Child Protective Services, Kennedy School of Government, Cambridge, Mass., April.

Gerstein, Dean, and Henrick Harwood, eds. 1990. Treating Drug Problems, vol. 1. Washington, D.C.: National Academy Press.

Goerge, Robert M., and Fred Wulczyn, 1998/99. "Placement Experiences of the Youngest Foster Care Population." Zero to Three 19 (3): 8-13.

Graham, Karen, Annette Feigenbaum, Anne Pastuszak, Irena Nulman, Rosanna Weksberg, Tom Einarson, Susan Goldberg, Stan Ashby, and Gideon Koren. 1992. "Pregnancy Outcome and Infant Development Following Gestational Cocaine Use by Social Cocaine Users in Toronto, Canada." Clinical and Investigative Medicine 15 (4): 384-94.

Griffith, Dan R. 1992. "Prenatal Exposure to Cocaine and Other Drugs: Developmental and Educational Prognoses." Phi Delta Kappan (September): 30-34.

Griffith, Dan R., Scott D. Azuma, and Ira J. Chasnoff. 1994. "Three-Year Outcome of Children Exposed Prenatally to Drugs." Journal of the American Academy of Child and Adolescent Psychiatry 33 (1): 20-27.

Guisti, Laura M. 1996. "Development of Children in Foster Care: Comparison of Battelle Screening Test Performance of Children Prenatally Exposed to Cocaine and NonExposed Children." Pp. 155-71 in Children with Prenatal Drug Exposure, edited by Lynette S. Chandler and Shelly J. Lane. New York: Hawthorn.

Gustavsson, Nora S. 1991. "Chemically Exposed Children: The Child Welfare Response." Child and Adolescent Social Work 8 (4): 297-307.

Hans, Sydney L. 1996. "Prenatal Drug Exposure: Behavioral Functioning in Late Childhood and Adolescence." NIDA Research Monograph 164: 261-76.

Hansen, Robin L., Jean M. Struthers, and Sidney M. Gospe, Jr. 1993. "Visual Evoked Potentials and Visual Processing in Stimulant Drug-Exposed Infants." Developmental Medicine and Child Neurology 35 (9): 798-805.

Harwood, Henrick, Douglas Fountain, and Gina Livermore. 1998. The Economic Costs of Alcohol and Drug Abuse in the United States, 1992. National Institute of Health publication no. 98-4327. Washington, D.C.: National Institute on Drug Abuse.

Hawley, Theresa Lawton, Tamara G. Halle, Ruth E. Drasin, and Nancy G. Thomas. 1995. "Children of Addicted Mothers: Effects of the 'Crack Epidemic' on the Caregiving Environment and the Development of Preschoolers." American Journal of Orthopsychiatry 65 (3): 364-79.

Horn, Wade F. 1994. "Implications for Policy-Making." Pp. 165-74 in When Drug Addicts Have Children: Reorienting Child Welfare's Response, edited by Douglas J. Besharov and Kristina W. Hanson. Washington, D.C.: Child Welfare League of America and American Enterprise Institute.

Horrigan, T. J., N. J. Piazza, and L. Weinstein. 1996. "The Substance Abuse Subtle Screening Inventory Is More Cost Effective and Has Better Selectivity than Urine Toxicology for the Detection of Substance Abuse in Pregnancy." Journal of Perinatology 16 (5): 326-30.

Hutchings, Donald E. 1993. "The Puzzle of Cocaine's Effects Following Maternal Use during Pregnancy: Are There Reconcilable Differences?” Neurotoxicology and Teratology 15 (5): $281-86$.

Jacobson, Joseph L., Sandra W. Jacobson, Robert J. Sokol, Susan S. Martier, Joel W. Ager, and Seetha Shankaran. 1994. "Effects of Alcohol Use, Smoking, and Illicit Drug Use on Fetal Growth in Black Infants." Journal of Pediatrics 124 (5): 757-64.

Johnson, Jeanne M., J. Anthony Seikel, Charles L. Madison, Shari M. Foose, and Keri D. Rinard. 1997. "Standardized Test Performance of Children with a History of Prenatal Exposure to Multiple Drugs/Cocaine." Journal of Communication Disorders 30 (1): 45-72.

Kerr, Barbara. 1994. Review of "Substance Abuse Subtle Screening Inventory." Pp. 249-51 in The Supplement to the Eleventh Mental Measurements Yearbook, edited by Jane Close Conoley, James C. Impara, and Linda L. Murphy. Lincoln, Nebr.: University of Nebraska Press.

Kliegman, R. M., D. Madura, R. Kiwi, I. Eisenberg, and T. Yamashita. 1994. "Relation of Maternal Cocaine Use to the Risks of Prematurity and Low Birth Weight." Journal of Pediatrics 124 (5): 751-56.

Lester, Barry M., Kiti Freier, and Lyn LaGasse. 1995. "Prenatal Cocaine Exposure and Child 
Outcome: What Do We Really Know?" Pp. 19-39 in Mothers, Babies, and Cocaine: The Role of Toxins in Development, edited by Michael Lewis and Margaret Bendersky. Hillsdale, N.J.: Erlbaum.

Lester, Barry M., Linda L. LaGasse, and Rosemarie Bigsby. 1998. "Prenatal Cocaine Exposure and Child Development: What Do We Know and What Do We Do?" Seminars in Speech and Language 19 (2): 123-46.

Lester, Barry M., Linda L. LaGasse, and Ronald Seifer. 1998. "Cocaine Exposure and Children: The Meaning of Subtle Effects.” Science 282: 633-34.

Lester, Barry M., Lyn LaGasse, Kitti Freier, and Susan Brunner. 1996. "Studies of Cocaine Exposed Human Infants.” NIDA Research Monograph 164: 175-210.

Light, Richard J. 1973. "Abused and Neglected Children in America: A Study of Alternative Policies." Harvard Educational Review 43 (4): 556-99.

Lowe, John B., Richard A. Windsor, Bryn Adams, Joyce Morris. 1986. "Use of a Bogus Pipeline Method to Increase Accuracy of Self-Reported Alcohol Consumption among Pregnant Women." Journal of Studies on Alcohol 47 (2): 173-75.

Lutiger, Beatrix, Karen Graham, Thomas R. Einarson, and Gideon Koren. 1991. "Relationship between Gestational Cocaine Use and Pregnancy Outcome: A Meta-analysis.” Teratology 44 (4): 405-14.

Malakoff, M. E., L. C. Mayes, R. S. Shottenfeld. 1994. "Language Abilities of Pre-School-Age Children Living with Cocaine-Using Mothers." American Journal on Addiction 3: $346-54$.

Massing, Michael. 1998. The Fix. New York: Simon \& Schuster.

Mathias, Robert. 1992. "Developmental Effects of Prenatal Drug Exposure May Be Overcome by Postnatal Environment." Nida Notes 7 (1): 14-16.

Mayes, Linda C. 1996. "Exposure to Cocaine: Behavioral Outcomes in Preschool and School-Age Children.” NIDA Research Monograph 164: 211-29.

Mayes, Linda C., and Marc H. Bornstein. 1995. "Developmental Dilemmas for CocaineAbusing Parents and Their Children.” Pp. 251-72 in Mothers, Babies, and Cocaine: The Role of Toxins in Development, edited by Michael Lewis and Margaret Bendersky. Hillsdale, N.J.: Erlbaum.

Mayes, Linda C., Richard H. Granger, Marc H. Bornstein, and Barry S. Zuckerman. 1992. "The Problem of Prenatal Cocaine Exposure: A Rush to Judgment." Journal of the American Medical Association 267 (3): 406-8.

Myers, Barbara J., Heather Carmichael Olson, and Karol Kaltenbach. 1992. "CocaineExposed Infants: Myths and Misunderstandings." Zero to Three 13 (August/September): 1-5.

National Association of Public Welfare Administrators (NAPCWA). 1991. "Working with Substance-Abusing Families and Drug-Exposed Children: The Child Welfare Response." Public Welfare 49 (4): 37-38.

National Center for Youth Law. 1995. Youth Law News 17 (July-October). San Francisco: National Center for Youth Law.

National Institute on Drug Abuse. 1994. National Pregnancy and Health Survey. Rockville, Md.: U.S. Department of Health and Human Services.

Needlman, Robert, Deborah A. Frank, Marilyn Augustyn, and Barry S. Zuckerman. 1995. "Neurophysiological Effects of Cocaine Exposure: Comparison of Human and Animal Investigations." Pp. 229-50 in Mothers, Babies, and Cocaine: The Role of Toxins in Development, edited by Michael Lewis and Margaret Bendersky. Hillsdale, N.J.: Erlbaum.

Neuspiel, Daniel R. 1995. "The Problem of Confounding in Research on Prenatal Cocaine Effects on Behavior and Development.” Pp. 95-109 in Mothers, Babies, and Cocaine: The Role of Toxins in Development, edited by Michael Lewis and Margaret Bendersky. Hillsdale, N.J.: Erlbaum.

Nulman I., J. Rovet, D. Altmann, C. Bradley, T. Einarson, and G. Koren. 1994. "Neurodevelopment of Adopted Children Exposed In Utero to Cocaine." Canadian Medical Association Journal 151: 1591-97.

Olson, Heather Carmichael, Therese M. Grant, Joan C. Martin, and Ann P. Streissguth. 1995. "A Cohort Study of Prenatal Cocaine Exposure: Addressing Methodological Concerns.” Pp. 129-62 in Mothers, Babies, and Cocaine: The Role of Toxins in Development, edited by Michael Lewis and Margaret Bendersky. Hillsdale, N.J.: Erlbaum.

Regan, Dianne O., Saundra M. Ehrlich, and Loretta P. Finnegan. 1987. "Infants of Drug 
Addicts at Risk for Child Abuse, Neglect, and Placement in Foster Care.” Neurotoxicology and Teratology 9 (4): 315-19.

Richardson, Gale A., M. L. Conroy, and Nancy L. Day. 1996. "Prenatal Cocaine Exposure: Effects on the Development of School-Age Children." Neurotoxicology and Teratology 18 (b): $627-34$.

Richardson, Gale A., and Nancy L. Day. 1994. "Detrimental Effects of Prenatal Cocaine Exposure: Illusion or Reality?" Journal of the American Academy of Child and Adolescent Psychiatry 33 (1): 28-34.

Robins, Lee N., and James L. Mills, eds. 1993. American Journal of Public Health Supplement: Effects of In Utero Exposure to Street Drugs 83 (suppl.): 3-32.

Roche Diagnostics. 1999. "Methods for Detecting Drug Abuse." http://www.boehringermannheim.com/rapid/drugsabuse/DoA_MethDrugs_EN.html (July 11, 1999).

Rydell, Peter, and Susan Everingham. 1994. Controlling Cocaine: Supply versus Demand Programs. Santa Monica, Calif.: RAND.

Sabol, Barbara J. 1994. "The Call on Agency Resources." Pp. 125-43 in When Drug Addicts Have Children: Reorienting Child Welfare's Response, edited by Douglas J. Besharov and Kristina W. Hanson. Washington, D.C.: Child Welfare League of America and American Enterprise Institute.

SASSI Institute. 1998. "The Reliability and Validity of the SASSI-3." November 17. Springville, Ind.: SASSI Institute.

Schutter, Linda S., and Richard P. Brinker. 1992. "Conjuring a New Category of Disability from Prenatal Cocaine Exposure: Are the Infants Unique Biological or Caretaking Casualties?" Topics in Early Childhood Special Education 11 (4): 84-111.

Schwartz, R. H., S. Bogema, and M. M. Thorne. 1990. "Evaluation of a Rapid Latex-Particle Agglutination-Inhibition Screening Assay for Cocaine in Urine." Journal of Pediatrics 117 (4): 670-72.

Singer, Lynn T., Toyoko S. Yamashita, Suzanne Hawkins, Diane Cairns, Jill Bailey, and Robert Kliegman. 1994. "Increased Incidence of Intraventricular Hemorrhage and Developmental Delay in Cocaine-Exposed, Very Low Birth Weight Infants." Journal of Pediatrics 124 (5): 765-71.

Sluder, Linda C., Lloyd R. Kinnison, and Dennis Cates. 1996/7. "Prenatal Drug Exposure: Meeting the Challenge." Childhood Education 73 (2): 66-69.

Toufexis, Anastasia. 1991. "Innocent Victims." Time, May 13, pp. 56-60.

Treaster, Joseph B. 1993. "For Children of Cocaine, Fresh Reasons for Hope." New York Times, February 16, p. 1.

U.S. Department of Health and Human Services. 1994. Substance Abuse among Women and Parents. Washington, D.C.: U.S. Department of Health and Human Services.

U.S. Department of Health and Human Services. 1996. The National Treatment Improvement Evaluation Study, Preliminary Report: The Persistent Effects of Substance Abuse TreatmentOne Year Later. Washington, D.C.: U.S. Department of Health and Human Services.

U.S. Department of Health and Human Services, Children's Bureau. 1997. National Study of Protective, Preventive and Reunification Services Delivered to Children and Their Families. Washington, D.C.: Government Printing Office.

U.S. General Accounting Office. 1994. Parental Drug Abuse Has Alarming Impact on Young Children. Washington, D.C: U.S. General Accounting Office.

U.S. General Accounting Office. 1997. Parental Substance Abuse: Implications for Children, the Child Welfare System, and Foster Care Outcomes. Washington, D.C.: U.S. General Accounting Office.

Vacc, Nicholas A. 1994. Review of "Substance Abuse Subtle Screening Inventory." In The Supplement to the Eleventh Mental Measurements Yearbook, edited by Jane Close Conoley, James C. Impara, and Linda L. Murphy. Lincoln, Nebr.: University of Nebraska Press.

van Baar, Anneloes. 1990. "Development of Infants of Drug Dependent Mothers." Journal of Child Psychology and Psychiatry 31 (6): 911-20.

van Baar, Anneloes, and B. M. T. de Graaf. 1994. "Cognitive Development at Preschool-Age of Infants of Drug-Dependent Mothers." Developmental Medicine and Child Neurology 36: 1063-75.

Waldfogel, Jane. 1998. The Future of Child Protection: How to Break the Cycle of Abuse and Neglect. Cambridge, Mass.: Harvard University Press. 
Walker, Clarice Dibble. 1994. "African American Children in Foster Care.” Pp. 145-52 in When Drug Addicts Have Children: Reorienting Child Welfare's Response, edited by Douglas J. Besharov and Kristina W. Hanson. Washington, D.C.: Child Welfare League of America and American Enterprise Institute.

Wolock, Isabel, and Stephen Magura. 1996. "Parental Substance Abuse as a Predictor of Child Maltreatment Re-reports." Child Abuse and Neglect 20 (12): 1183-93.

Yolton, Kimberly A., and Rosemary Bolig. 1994. "Psychosocial, Behavioral, and Developmental Characteristics of Toddlers Prenatally Exposed to Cocaine." Child Study Journal 24 (1): 49-68.

Zuckerman, Barry S. 1994. "Effects on Parents and Children." Pp. 49-64 in When Drug Addicts Have Children: Reorienting Child Welfare's Response, edited by Douglas J. Besharov and Kristina W. Hanson. Washington, D.C.: Child Welfare League of America and American Enterprise Institute.

Zuckerman, Barry S., and Deborah A. Frank. 1992. “'Crack Kids': Not Broken.” Pediatrics 89 (2): 337-39.

$\rightarrow$ - 1994. "Prenatal Cocaine Exposure: Nine Years Later." Pediatrics 124 (5): 731-33.

\section{Notes}

We are grateful to Barry Lester and Barry Zuckerman for their help with the literature review. The National Center for Youth Law provided advice on state reporting laws. We would also like to thank two anonymous reviewers for helpful comments.

1. There is a wide range of estimates regarding the number of children who are exposed to crack cocaine in utero, and none of the estimates are considered completely reliable (see Robins and Mills 1993; Frank, Bresnahan, and Zuckerman 1996).

2. Parental substance abuse has been linked to child abuse and neglect reports and to repeat reports. Substance-exposed children enter care at higher rates and at younger ages, experience a greater number of placements, and remain in care longer than nonexposed children. And children whose parents use drugs are less likely to return home from foster care than those whose parents do not use drugs (Regan, Ehrlich, and Finnegan 1987; Gustavsson 1991; Famularo, Kinscherff, and Fenton 1992; Barth 1994; Horn 1994; Walker 1994; Barth and Needell 1996; Wolock and Magura 1996).

3. The 1991 National Household Survey on Drug Abuse found that 12.9 million children (18.8 percent of all children) had a parent who had used drugs in the past year, including 6.2 million children (9.2 percent of all children) whose parent had used drugs in the past month (see U.S. Department of Health and Human Services 1994, p. 39). Data from the National Institute on Drug Abuse (1994) suggest that over 1 million children are prenatally exposed to alcohol or illicit substances each year.

4. According to the 1991 National Household Survey on Drug Abuse, 10.8 percent of $0-2$-year-olds had a parent who had used drugs in the past month, a rate only slightly higher than that for children of all ages (9.2 percent).

5. The term "bio-underclass" was used by the Washington Post, September 17, 1989 (cited in Myers et al. 1992, p. 2). Others used the term "biologic underclass" (see, e.g., Toufexis 1991).

6. It should also be noted that publication biases have been cited in the literature indicating that studies that result in adverse findings related to exposure have been shown to have a greater chance of being published than studies that do not (Robins and Mills 1993; Neuspiel 1995; Frank et al. 1996).

7. With the exception of Graham et al. (1992), all of the current studies have focused on low-income women and children, while allowing for the possibility that other conditions of poverty have influenced findings.

8. While substance-use rates have been shown to be similar among black and white pregnant women, black women are more likely than white women to be reported to the authorities for substance use during pregnancy (Chasnoff, Landress, and Barrett 1990). Furthermore, minority children are more likely than white children to enter the child welfare system due to parental substance use (Gustavsson 1991).

9. See also the description of a crack-addicted mother in Massing (1998), pp. 29-46. 
10. Lester, LaGasse, and Bigsby (1998) found in their review of 76 studies that only three had used meconium testing.

11. Chasnoff et al. (1989) found improved in utero growth for exposed children whose mothers discontinued use after the first trimester of pregnancy. Furthermore, Hutchings (1993) suggests that the adverse teratogenic effects of prenatal exposure may occur only for those infants who are exposed to the highest doses of cocaine.

12. Jacobson et al. (1994) explain that cocaine exposure tends to affect birth size (weight, length, and head circumference) indirectly as a consequence of shorter gestation and poor maternal nutrition. Other studies have found few differences in length, weight, and head circumference between exposed and nonexposed infants born preterm (Collett 1997) and no differences in intrauterine growth between exposed and nonexposed infants (Chasnoff et al. 1985).

13. Frank and Zuckerman (1993) conclude that birth defects are relatively rare among crack-exposed infants. Furthermore, Richardson and Day (1994) report that, controlling for socioeconomic variables and other drug use, prenatal cocaine exposure appears not to affect infant growth and morphology significantly.

14. The one study that found differences in cognitive development was van Baar and de Graaff (1994).

15. Lester, LaGasse, and Seifer (1998) further explored these differences in their metanalysis. Of the 101 studies that met their inclusion criteria, only eight focused on schoolage children. They conclude that, when considered together, these eight studies suggest that cocaine exposure may result in subtle negative effects on $I Q$ and slightly larger negative effects on specific language abilities. The researchers estimate that these subtle forms of brain damage will increase the number of children who need special education or fail in school, which could result in additional education costs of up to $\$ 352$ million per year.

16. Furthermore, Zuckerman and Frank (1994) interpret the findings of Singer et al. (1994) as suggesting that the combination of prenatal exposure and foster care placement may result in greater risks for children than either factor alone.

17. For a further discussion of the effectiveness of home visiting, see Future of Children (1993) and Future of Children (1999), both special issues devoted to home visiting. For an overview of the evidence on the efficacy of substance-abuse treatment services, see Gerstein and Harwood (1990); Rydell and Everingham (1994); and U.S. Department of Health and Human Services (1996).

18. Current evidence suggests that substance-exposed infants are more likely to enter care than are other children. Richard P. Barth (1994) reports that 80 percent of children who were both born prenatally exposed to illicit substances and known to the child welfare system were placed in foster care in 1990. Chasnoff (1998) cites the U.S. General Accounting Office in reporting that 55 percent of the very young children placed in substitute care in 1991 were prenatally exposed to some form of cocaine and that an additional 11 percent were prenatally exposed to alcohol or other drugs.

19. For an excellent overview of the impact of parental substance abuse on the child welfare system, see U.S. General Accounting Office (1997).

20. The other way in which state legislatures and Congress have responded is by changing regulations regarding permanency planning for children exposed to crack cocaine or other substances. We intend to review these initiatives in future work; to cover them here would be beyond the scope of this article.

21. Drug exposure can be tested through both laboratory tests and on-the-spot tests, which may measure the presence and amount of a specific substance in various samples, including urine, blood, hair, and saliva. Some tests, commonly referred to as qualitative tests, identify only whether or not a specific substance is present or absent at a predetermined concentration in a given sample. Quantitative tests, however, show both the presence and quantity (concentration) of a specific substance in a given sample (Roche Diagnostics 1999).

22. It is probably safe to make these assumptions because it is not likely that less accurate instruments would be useful for testing. Furthermore, urine testing is one of the most commonly used tests, and Schwartz, Bogema, and Thorne (1990) report that one enzyme immunoassay urine test, the EZ-SCREEN, had a sensitivity (ability to accurately identify exposure in exposed children) of 95 percent, a specificity (ability to identify nonexposure in nonexposed children) of 89 percent, and an efficiency of 87 percent for samples contain- 
ing $300 \mathrm{ng} / \mathrm{mL}$ or more cocaine metabolites. They found two false negatives (5.26 percent) and five false positives (13.16 percent) out of 38 samples.

23. Rates as high as 30 percent have been reported at high-risk hospitals (see Harwood, Fountain, and Livermore 1998).

24. These factors may include costs to mothers, physician or managed-care support, and costs to the doctor/patient relationship. Both testing and screening policies may pose significant costs to mothers in terms of loss of privacy and stigma. However, the extent to which mothers' privacy is invaded may be limited if the results of screening or testing are kept confidential. In such cases, mothers could still be referred for treatment; however, participation would be on a purely voluntary basis, and substance exposure status would not be reported to CPS or any other source. A confidentiality policy may also limit stigma regarding substance-using pregnant women, as their substance-abuse statuses would only be known by their primary-care physicians. If, however, positive results were not kept confidential, one could argue that screening is less invasive than testing in regard to maternal privacy, because in the case of screening, mothers may believe that they have greater control over what they choose to disclose. In regard to physician or managed-care support, both groups may be more likely to support screening, as it is much less costly than testing and is easy to administer. The SASSI, for instance, costs about two dollars per administration, can be administered in paper or computer form (or orally) by almost anyone, is readable at the fifth-grade level, and can be completed in 10-15 minutes and scored in 1-10 minutes. Furthermore, it is "insulated to the respondent's level of honesty or faking" (Vacc 1994, p. 252). By comparison, while many urine-based drug tests can be easily administered in a physician's office, their cost of administration is about two to 10 times that of the SASSI (approximately \$5-\$20 per administration, depending on the number of drugs being tested). In addition, the SASSI offers the added benefit of testing for substance addiction in general rather than for the presence of specific drugs. It therefore identifies alcohol addiction, which is not generally picked up in toxicology tests. The SASSI has also been found to be more effective and less costly at identifying substance abuse than has toxicology testing (Horrigan, Piazza, and Weinstein 1996). Finally, although the doctor/patient relationship may be adversely affected under either screening or testing, the overall effect on the relationship may be more heavily influenced by reporting requirements (i.e., policies regarding confidentiality of results) than by the method of determining substance abuse. Each of these factors should be considered by policy makers when considering the costs and benefits of screening and testing policies.

25. The SASSI Institute (1998) reports that the SASSI-3 has a sensitivity of 94 percent and a specificity of 94 percent.

26. For the purposes of this analysis, we assume that qualitative, on-the-spot urine tests would most likely be used for national screening. We make this assumption for several reasons: (1) they are less expensive and easier to administer than other tests, (2) there is a large amount of empirical data regarding these tests, (3) many commercial tests of this type are available (e.g., the EZ-SCREEN, OnTrak, and Verdict tests), (4) drugs are both more highly concentrated and detectable over longer periods of time in urine than in blood, and (5) urine is relatively easy to collect and analyze as compared to many other sample types (Roche Diagnostics 1999).

27. Although the topic of this article is children who are prenatally exposed to cocaine, we should note that screening also has potential as a strategy to identify the larger group of children who have been prenatally exposed to other drugs or alcohol as well as children other than newborns who are affected by parental substance abuse. According to the National Institute on Drug Abuse (1994) report on substance abuse among parents, about one in five American children had a parent who used drugs in the past year. Furthermore, the National Institute on Drug Abuse reports that more than 1 million children are born prenatally exposed to illicit drugs or alcohol each year. This figure represents more than a quarter of all births. Thus, if we were to extend our analysis to substance exposure more generally, we could safely use a value of $20-25$ percent for $P(I)$ in our analysis.

28. See, e.g., Lowe et al. (1986).

29. A complete discussion of home visiting, while important, is beyond the scope of this article. For a further discussion, see Future of Children (1993) and Future of Children (1999), which are special issues devoted to home visiting.

30. For further discussion of cross training and other training issues, see Waldfogel (1998). 